\title{
Brain derived neurotrophic factor (BDNF) release from the human brain in patients with type 2 diabetes-possible influence of venous anatomy and comorbid major depressive disorder
}

\author{
G. W. Lambert • M. P. Schlaich • M. D. Esler
}

Received: 21 May 2007 / Accepted: 6 June 2007 / Published online: 19 July 2007

(C) Springer-Verlag 2007

Keywords Affective disorders · Brain · Glucose · Insulin · Neurotrophin

\begin{abstract}
Abbreviations
BDNF brain-derived neurotrophic factor

MDD major depressive disorder
\end{abstract}

To the Editor: Krabbe et al. [1] recently examined whether brain-derived neurotrophic factor (BDNF) plays a role in human glucose metabolism. By examining a large cohort of subjects with or without type 2 diabetes in the presence or absence of obesity they concluded that plasma BDNF levels were reduced in patients with type 2 diabetes and were inversely associated with fasting plasma glucose levels. The authors, using direct internal jugular vein blood sampling, extended this observation by apparently demonstrating that elevated blood glucose levels inhibit the release of BDNF from the human brain. While the authors' observations shed new light into a possible role of BDNF in type 2 diabetes, there are a number of points that require further clarification.

The authors propose that decreased BDNF may be a pathogenic factor linking depression and type 2 diabetes, yet, in their study [1], they did not adequately screen their cohort for the comorbid presence of major depressive disorder (MDD). Neurotrophic factors are thought to play an important role in the aetiology of MDD [2, 3]. Given

G. W. Lambert $(\bowtie) \cdot$ M. P. Schlaich $\cdot$ M. D. Esler

Human Neurotransmitters Laboratory,

Baker Heart Research Institute,

Melbourne VIC 3004, Australia

e-mail: gavin.lambert@baker.edu.au that a substantial proportion of people with major depressive disorder do not receive adequate treatment [4], using 'current intake of antidepressive medication' as a surrogate for screening for MDD is inadequate. Indeed, the authors, in their diabetes cohort, document five cases out of 96 as currently taking antidepressants. Given that the presence of diabetes doubles the odds of comorbid MDD [5] the authors may have underestimated the prevalence of MDD.

Without recourse to some type of venous scanning methodology it is difficult to reconcile the precise origin of BDNF in the internal jugular venous effluent. Indeed, the cerebral venous sinus drainage is asymmetrical, with the superior sagittal sinus predominantly draining the cerebral hemispheres [6]. As the sinus nears the internal occipital protuberance it deviates to one side or the other and forms the transverse sinus, which in turn, becomes an internal jugular vein. Investigations from our group indicate that the superior sagittal sinus drains into the right internal jugular vein in approximately $50 \%$ of individuals [7-9]. Using technetium blood flow scans it is possible to determine the route of drainage of the superior sagittal sinus [7]. Importantly, cerebral neurotransmitter turnover, in some instances, also displays asymmetry [7, 8], making it possibly important to differentiate between cortical and subcortical drainage. Whether internal jugular BDNF overflow is markedly different between cortical and subcortical brain regions is not known.

Using percutaneously placed venous sampling catheters positioned high in an internal jugular vein, Krabbe and colleagues state that they measured 'jugular-arterial (Av) concentration differences' as an index of brain production. Accordingly, using this formula, positive veno-arterial concentration gradients would indeed indicate an overflow of BDNF from the brain into the circulation. Contrary to the 
authors' conclusion, Fig. 2 of their article clearly shows a negative veno-arterial BDNF concentration difference, indicative of BDNF extraction from plasma by the brain, rather than output to plasma. Without any raw data detailing arterial or internal jugular BDNF plasma concentrations it is difficult to evaluate the authors' contention that BDNF overflow from the brain is inhibited by elevated blood glucose.

Duality of interest The authors declare that there is no duality of interest associated with this manuscript.

\section{References}

1. Krabbe KS, Nielsen AR, Krogh-Madsen R et al (2007) Brain-derived neurotrophic factor (BDNF) and type 2 diabetes. Diabetologia 50:431-438

2. Duman RS, Heninger GR, Nestler EJ (1997) A molecular and cellular theory of depression. Arch Gen Psychiatry 54:597-606
3. Eikelis N, Esler M, Barton D, Dawood T, Wiesner G, Lambert G (2006) Reduced brain leptin in patients with major depressive disorder and in suicide victims. Mol Psychiatry 11:800-801

4. Kessler RC, Berglund P, Demler O et al (2003) The epidemiology of major depressive disorder: results from the National Comorbidity Survey Replication (NCS-R). JAMA 289:3095-3105

5. Anderson RJ, Freedland KE, Clouse RE, Lustman PJ (2004) The prevalence of comorbid depression in adults with diabetes: a metaanalysis. Diabetes Care 24:1069-1078

6. Gray H (1980) Angiology and neurology. In: Williams PL, Warwick R (eds) Gray's anatomy, 36th edn. Churchill Livingstone, Edinburgh, pp 738-751

7. Lambert GW, Eisenhofer G, Cox HS et al (1991) Direct determination of homovanillic acid release from the human brain, an indicator of central dopaminergic activity. Life Sci 49:10611072

8. Ferrier C, Jennings GL, Eisenhofer G et al (1993) Evidence for increased noradrenaline release from subcortical brain regions in essential hypertension. J Hypertens 11:1217-1227

9. Lambert G, Johansson M, Agren H, Friberg P (2000) Evidence of reduced central nervous system norepinephrine and dopamine turnover in patients with depressive illness. Arch Gen Psychiatry $57: 787-793$ 